\title{
Clinical characteristics and electroencephalogram analysis of levetiracetam in the treatment of children with febrile seizure recurrence
}

\author{
XUE-CHAO LI ${ }^{1}$, LING-LING LU ${ }^{2}$, JIAN-ZHONG WANG ${ }^{1}$, MIAO WANG ${ }^{1}$, \\ YU GAO ${ }^{1}$, YE-XIN LIN ${ }^{3}$ and ZHONG-HOU HAN ${ }^{1}$ \\ ${ }^{1}$ Department of Pediatrics, Maternal and Child Care Center of Qinhuangdao, Qinhuangdao, Hebei 066000; \\ ${ }^{2}$ Centers for Disease Control and Prevention of Qinhuangdao, Qinhuangdao, Hebei 066009; ${ }^{3}$ Department of \\ Children ICU, Shengjing Hospital of China Medical University, Shenyang, Liaoning 110004, P.R. China
}

Received September 8, 2016; Accepted May 11, 2017

DOI: $10.3892 /$ etm.2017.4738

\begin{abstract}
Febrile seizure is the most common neurologic disorder in infants and children. This study aimed to elaborate safe and effective therapy for preventing FS recurrence by levetiracetam (LEV). A prospective study was performed in two groups of children, the no treatment group $(n=51,24.1 \pm 9.0$ months) and the LEV treatment group ( $n=45,23.3 \pm 8.9$ months). The findings demonstrated that a significant difference $(\mathrm{P}<0.01)$ was observed between the no treatment group $51.0 \%(26 / 51)$ and LEV treatment group $15.5 \%(7 / 45)$ in terms of FS recurrence after 50 weeks. FS recurrence/fever episode was $12.4 \%$ (12/97) in the LEV treatment group and 51.8\% (57/110) in the no treatment group. Furthermore, LEV administration significantly improved $(\mathrm{P}<0.001)$ epileptiform + nonspecific EEG abnormalities $(17.8 \% ; 8 / 45)$, as compared with the no treatment group $(68.6 \% ; 35 / 51)$. In conclusion, LEV could function as an effective therapeutic agent for the prevention of FS recurrence and reducing the frequency of fever episodes. Furthermore, LEV administration significantly improved nonspecific EEG abnormalities, which may be used as a clinical monitoring index for LEV treatment in patients with FS.
\end{abstract}

\section{Introduction}

Febrile seizure (FS) is induced by fever and is the most common form of childhood seizure, affecting 2-5\% of children aged six months to five years worldwide (1). FS is age-dependent and is uncommon before 6 months and after 5 years of age (2). The overall rate of recurrence after the first episode is $30-37 \%$, however, this value may be $\sim 50 \%$ in children aged $<1$ year

Correspondence to: Dr Zhong-Hou Han, Department of Pediatrics, Maternal and Child Care Center of Qinhuangdao, 452 Hongqi Road, Qinhuangdao, Hebei 066000, P.R. China

E-mail: cba666@126.com

Key words: levetiracetam, febrile seizure, electroencephalogram old (3). Emerging evidence suggests that prolonged or recurrent FS increases the risk of cortex neuron apoptosis (4), hippocampal injury (5) and poor cognitive outcomes (6). In clinical trials, avoiding brain injury is important for the prevention of FS recurrence $(7,8)$. Therefore, improved prevention and treatment approaches are required for FS clinical trials.

Treatment trials for FS suggest that there are no obvious differences between intense routine use and intermittent use of the antipyretic agents in reducing the incidence of FS recurrence (9). Furthermore, antipyretic agents are ineffective for the prevention of FS recurrence and for the lowering of body temperature in patients with a febrile episode that leads to recurrent FS (10). At present, the medication guidelines do not recommend the use of continuous or intermittent therapy with neuroleptics, such as benzodiazepines, after a simple febrile seizure $(11,12)$. In previous studies, antiepileptic drugs (AEDs), such as phenobarbital and valproic acid, are considered effective at protecting against the recurrence of FS; however, long-term treatment with these drugs may be associated with a wide spectrum of adverse effects, including behavioral disturbances, irritability, hyperactivity and decreased cognitive function $(13,14)$. Intermittent therapy with oral diazepam also results in a reduced risk of recurrent FS, although the effectiveness is limited (15).

Levetiracetam (LEV) is a novel AED that is reported to have far less potential side effects in the treatment of brain injury (16). Evidence has shown that LEV can effectively prevent FS recurrence (17). A previous systematic review and meta-analysis suggested that LEV is associated with a lower adverse drug reaction rate and appears to have a similar efficacy to phenytoin for seizure prophylaxis (18). However, further investigation into the safety and efficacy of LEV in FS is required. This single blind, randomized prospective trial aimed to evaluate the effectiveness of LEV in preventing FS recurrence.

\section{Materials and methods}

Patients and study design. The study group included 96 children (23.7 \pm 8.9 months) diagnosed with FS between July 2010 
and May 2015 in the Department of Pediatrics at Maternal and Child Care Center of Qinhuangdao (Qinhuangdao, China). This prospective study was performed in two groups of children: 51 children (27 male and 24 female) in the no treatment group and 45 children ( 24 male and 21 female) in the LEV treatment group. A statistician randomly assigned each child to either the no treatment group or LEV treatment group, and the clinicians who followed-up these children did not know their randomization. FS was defined as a seizure associated with a body temperature of $\geq 38^{\circ} \mathrm{C}$ in the absence of central nervous system infection. Criteria for inclusion were as follows: Children with a history of two or more episodes of FS within the last 3 months, at least one seizure recurrence within the last 2 weeks, and onset age between 6 months and 5 years. The study was approved by the regional Ethics Committee of Maternal and Child Care Center of Qinhuangdao. Written informed consent was obtained from the parents of the children. As shown in Fig. 1, patients in the LEV treatment group received oral LEV (UCB, Brussels, Belgium) at a dose of $15-30 \mathrm{mg} / \mathrm{kg}$ twice daily at the onset of fever $\left(38^{\circ} \mathrm{C}\right)$ for 1 week (therapy period), followed by a dose increase or decrease every 2 days until complete withdrawal at the beginning of the second week (observation period). LEV was effective in all children after the first dose. FS recurrence and fever episodes were measured during the 48 -week period following the LEV administration period of 2 weeks, and body temperature was observed at home.

All children with FS were hospitalized, and electroencephalograms (EEGs) were performed 1 to 2 days later, after patients became afebrile; depending on individual circumstances, some patients underwent EEGs after discharge. The sensitivity was set at $10 \mu \mathrm{V} / \mathrm{mm}$ with low-frequency filter of $0.5 \mathrm{~Hz}$, high-frequency filter of $60 \mathrm{~Hz}$. Subsequent EEGs were performed at weeks 20 and 50. Each EEG was interpreted independently by two pediatric neurologists. EEG findings were classified as normal, epileptiform, or nonspecific with regard to abnormalities.

Statistical analysis. Groups were compared statistically using the Chi-square test. All statistical analyses were performed using SPSS v12.0 (SPSS, Inc., Chicago, IL, USA). P $<0.05$ was considered to indicate a statistically significant difference.

\section{Results}

Clinical characteristics of the patients. Clinical characteristics of the children are shown in Table I. A total of 96 children (51 males and 45 females) met the inclusion criteria and were classified into two groups: No treatment group $(\mathrm{n}=51)$ and LEV group $(n=45)$. The 27 males and 24 females in the no treatment group did not receive LEV administration in the primary analysis, whereas the 24 males and 21 females in the LEV group received oral LEV (10-30 mg/kg twice daily) in the initial treatment period. No differences were observed in terms of age, sex, family history, prolonged duration of FS, or body temperature in the two groups before LEV administration (Table I). Among the subjects, $11.5 \%$ (11/96) were patients with complex FS, and 88.5\% (85/96) were patients with simple FS (Table II).

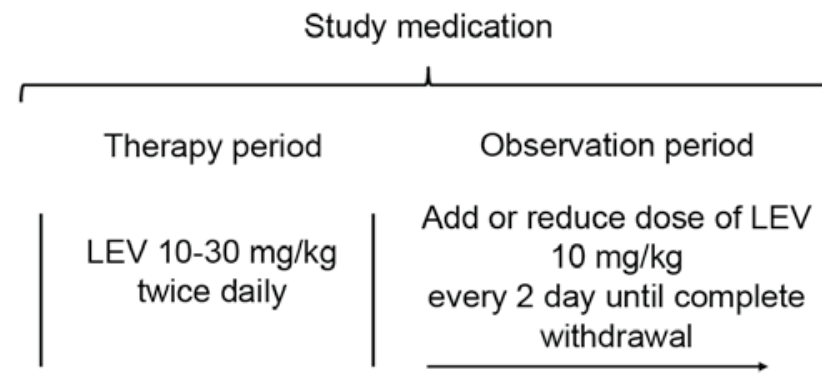

Week 1

At the beginning of the week 2

Figure 1. Study medication. Patients with FS in the LEV treatment group received oral LEV at a dose of $15-30 \mathrm{mg} / \mathrm{kg}$ twice daily at the onset of fever $\left(\geq 38^{\circ}\right)$ for 1 week (therapy period), followed by a dose increase or decrease every 2 days until complete withdrawal at the beginning of the second week (observation period). LEV was effective in all children after the first dose. LEV, levetiracetam; FS, febrile seizure.

$L E V$ reduces the risk of $F S$ recurrence. In this study, multiple recurrences were associated with early administration. Recurrences of FS were recorded during the 48-week period following LEV administration. In the LEV treatment group, $2.2 \%(1 / 45)$ of second attacks occurred during the 10 weeks after the initial week, $6.7 \%$ (3/45) within 20 weeks, $8.9 \%(4 / 45)$ within 30 weeks, $11.1 \%$ (5/45) within 40 weeks and $15.5 \%$ (7/45) within 50 weeks. In addition, 9.8\% (5/51) of recurrences occurred during the 10 weeks after the initial week in the no treatment group, $17.6 \%$ (9/51) within 20 weeks, $27.4 \%(14 / 51)$ within 30 weeks, $39.2 \%(20 / 51)$ within 40 weeks and $51.0 \%$ (26/51) within 50 weeks (Fig. 2A; Table I). In the LEV treatment group, 45 children experienced 97 febrile episodes. Among these 45 children, 7 children experienced 12 recurrences of FS. In the no treatment group, 51 children experienced 110 febrile episodes. Among these 51 children, 26 children experienced 57 recurrences of FS during the 48-week period following LEV administration (Fig. 2A and B). As shown in Fig. 2B, the FS recurrence/fever episode was $12.4 \%$ (12/97) in the LEV treatment group and 51.8\% (57/110) in the no treatment group. Furthermore, the body temperatures of patients in the no treatment group $(n=51)$ and LEV treatment group $(n=45)$ were divided into four degrees: 37.0-37.9, 38.0-38.9, 39.0-39.9, and $\geq 40^{\circ} \mathrm{C}$. There was a significant difference between the two groups $(\mathrm{P}=0.017$; Table III). These results suggest that oral LEV is an effective therapeutic method of reducing FS recurrence.

EEG analysis. EEGs were performed 1-2 days after treatment when all of the children with FS were hospitalized and became afebrile. EEG findings were classified as normal, epileptiform, or nonspecific with regard to abnormalities. As shown in Fig. 3A, EEG abnormalities (focal slow waves) were detected at week 0 prior to the start of LEV administration. These EEG abnormalities were improved after LEV treatment in the LEV group at weeks 20 and 50 (Fig. 3B and C, respectively). In the LEV treatment group, EEG abnormalities were found in 8 children (17.8\%), including 2 children (4.4\%) with epileptiform abnormalities and 6 children (13.4\%) with nonspecific abnormalities (6/45). In the no treatment group, EEG abnormalities were detected in 35 children (68.6\%), 
Table I. Clinical profiles of the patients.

\begin{tabular}{|c|c|c|c|}
\hline Characteristics & $\begin{array}{l}\text { No treatment } \\
\quad(n=51)\end{array}$ & $\begin{array}{c}\text { LEV } \\
(n=45)\end{array}$ & P-value \\
\hline Age at FS onset (months) ${ }^{\mathrm{a}}$ & $24.6(7-63)$ & $27.1(8-60)$ & 0.137 \\
\hline Male/female & $27 / 24$ & $24 / 21$ & $>0.99$ \\
\hline Family history of seizures ${ }^{b}$ & $24(47.0)$ & $18(40.0)$ & 0.487 \\
\hline Prolonged duration of $\mathrm{FS} \geq 15 \mathrm{~min}^{\mathrm{b}}$ & $4(7.8)$ & $2(4.4)$ & 0.792 \\
\hline Body temperature $\left({ }^{\circ} \mathrm{C}\right)$ at onset admission ${ }^{a}$ & $38.2(37.1-40.3)$ & $38.7(37.0-41.2)$ & 0.843 \\
\hline Interval between the onset of fever and seizure $(h)^{a}$ & $9.7(0.0-48.3)$ & $10.3(0.0-51.7)$ & $>0.99$ \\
\hline Multiple FSs before admission ${ }^{\mathrm{b}}$ & $5(9.8)$ & $6(13.3)$ & 0.588 \\
\hline Use of LEV treatment before admission ${ }^{\mathrm{b}}$ & $10(19.6)$ & $8(17.8)$ & 0.819 \\
\hline Recurrence of FS after with or without LEV treatment ${ }^{\mathrm{b}}$ & $26(51.0)$ & $7(16.0)$ & $<0.001$ \\
\hline
\end{tabular}

Data are presented as the ${ }^{\mathrm{a}}$ median (range) or ${ }^{\mathrm{b}}$ number $(\%)$. FS, febrile seizure; LEV, levetiracetam.

Table II. Distribution of simple FS and complex FS.

\begin{tabular}{lcr}
\hline & \multicolumn{2}{c}{ Patients } \\
\cline { 2 - 3 } Type of FS & No treatment & LEV \\
\hline Simple FS & 46 & 39 \\
Complex FS & 5 & 6 \\
Prolonged duration ( $\geq 15$ min) & 4 & 2 \\
Recurrent seizures within the same & 1 & 1 \\
febrile illness over a 24-h period & & \\
Focal onset & 0 & 3 \\
\hline
\end{tabular}

FS, febrile seizure; LEV, levetiracetam.

including 8 children (15.7\%) with epileptiform abnormalities and 27 children $(52.9 \%)$ with nonspecific abnormalities. These results demonstrated that FS patients treated with LEV exhibited significantly improved $(\mathrm{P}<0.001)$ EEG abnormalities, as compared with the no treatment group at week 50 (Table IV). Furthermore, clinical characteristics, including age, family history of FS and duration of seizure, in the normal and abnormal EEG groups with FS are shown in Table V. Our findings indicated that age and duration of seizure had no apparent association with abnormal EEG findings. However, family history of FS was demonstrated to be significantly associated with abnormal EEGs $(\mathrm{P}=0.009)$.

\section{Discussion}

FS is benign in children and is typically associated with a good prognosis. In most instances, FS is closely related to upper respiratory tract infections, and the majority of children recover without complications within a few days (19). However, prolonged or recurrent FS has been shown to increase the risk for developing subsequent temporal lobe epilepsy in adults (5). More importantly, recurrent FS may result in brain structure damage, particularly in the

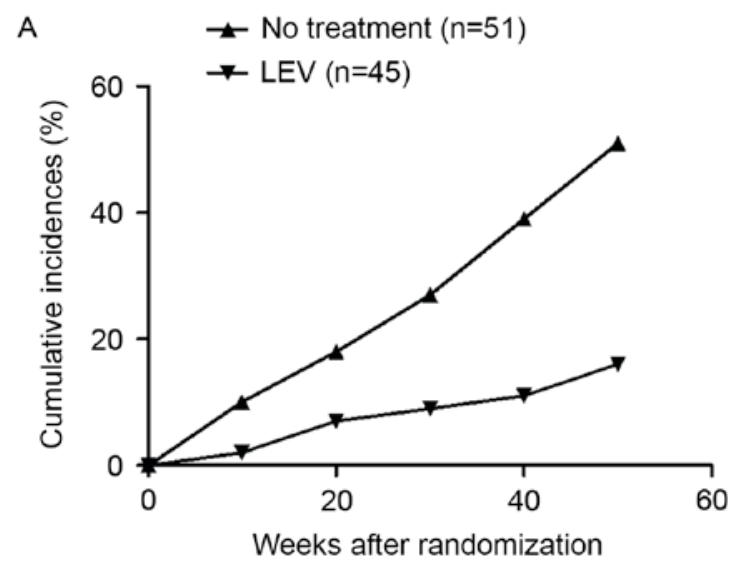

B

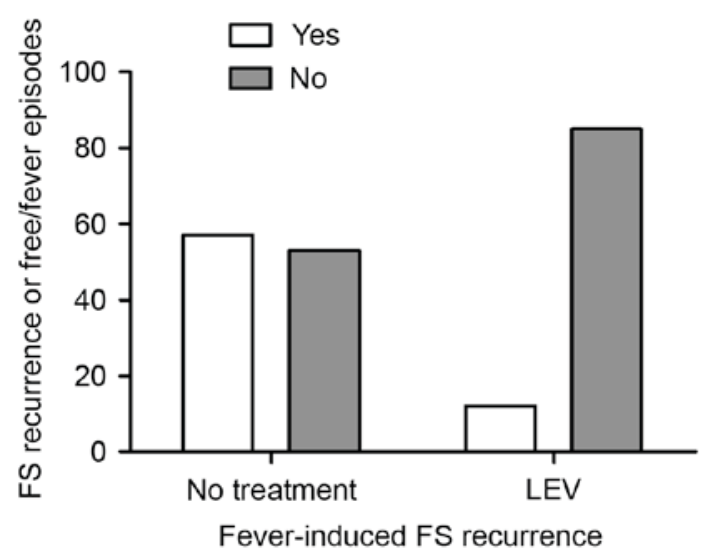

Figure 2. LEV reduces the risk of FS recurrence. (A) Cumulative incidence of recurrent FS in the no treatment group and the LEV treatment group during the experimental period. (B) FS recurrence or free frequency/fever episode in the no treatment group and the LEV treatment group during the experimental period. LEV, levetiracetam; FS, febrile seizure.

hippocampus $(5,20)$. The present findings demonstrated that $\sim 51 \%$ of the children had undergone FS recurrences within 12 months from their first FS. These findings correlate with the data collected in previous reports $(17,21,22)$. In our study, it was demonstrated that intermittent oral LEV effectively 
Table III. Episodes of fever in patients with or without LEV treatment.

\begin{tabular}{lcccc}
\hline $\begin{array}{l}\text { Temperature } \\
\left({ }^{\circ} \mathrm{C}\right)\end{array}$ & No treatment & LEV & $\chi^{2}$ & P-value \\
\hline $37.0-37.9$ & 9 & 22 & 2.157 & 0.017 \\
$38.0-38.9$ & 23 & 13 & & \\
$39.0-39.9$ & 17 & 7 & & \\
$\geq 40.0$ & 2 & 3 & & \\
\hline
\end{tabular}

LEV, levetiracetam.

Table IV. Electroencephalographic characteristics of patients with or without LEV treatment were collected at week 50.

\begin{tabular}{lccr}
\hline $\begin{array}{l}\text { EEG characteristics, } \\
\mathrm{N}(\%)\end{array}$ & $\begin{array}{c}\text { No treatment } \\
(\mathrm{n}=51)\end{array}$ & $\begin{array}{c}\text { LEV } \\
(\mathrm{n}=45)\end{array}$ & P-value \\
\hline Normal & $16(31.4)$ & $37(82.2)$ & $<0.001$ \\
Epileptiform abnormalities & $8(15.7)$ & $2(4.4)$ & 0.143 \\
Nonspecific abnormalities & $27(52.9)$ & $6(13.4)$ & $<0.001$ \\
Generalized slow waves & $15(29.4)$ & $3(6.7)$ & \\
Focal slow waves & $2(3.9)$ & $1(2.2)$ & \\
$\begin{array}{l}\text { Generalized spike } \\
\text { and waves }\end{array}$ & $1(2.0)$ & $2(4.4)$ & \\
$\begin{array}{l}\text { Abnormal theta rhythms } \\
\text { Asymmetric background }\end{array}$ & $6(11.8)$ & $0(0.0)$ & \\
$\begin{array}{l}\text { Epileptiform + Nonspecific } \\
\text { abnormalities }\end{array}$ & $35(68.6 \%)$ & $8(17.8 \%)<0.001$ \\
\end{tabular}

FS, febrile seizure; LEV, levetiracetam.

Table V. Clinical variables associated with abnormal EEG.

\begin{tabular}{lccc}
\hline Variable & $\begin{array}{c}\text { Normal } \\
\text { EEG }\end{array}$ & $\begin{array}{c}\text { Abnormal } \\
\text { EEG }\end{array}$ & P-value \\
\hline Age (months) & & & 0.362 \\
$\quad<24$ & 13 & 20 & \\
$\geq 24$ & 19 & 44 & \\
Family history of FS & & & 0.009 \\
$\quad$ Yes & 5 & 27 & \\
$\quad$ No & 27 & 37 & \\
Duration of seizure (min) & & & \\
$\quad<15$ & 31 & 59 & 0.655 \\
$\geq 15$ & 1 & 5 & \\
\hline
\end{tabular}

FS, febrile seizure; EEG, electroencephalography.

prevented FS recurrence in the LEV group $(15.6 \% ; 7 / 45)$ as compared with the control group $(51.0 \% ; 26 / 51)$. No adverse effects occurred in the patients. These findings suggest that
A

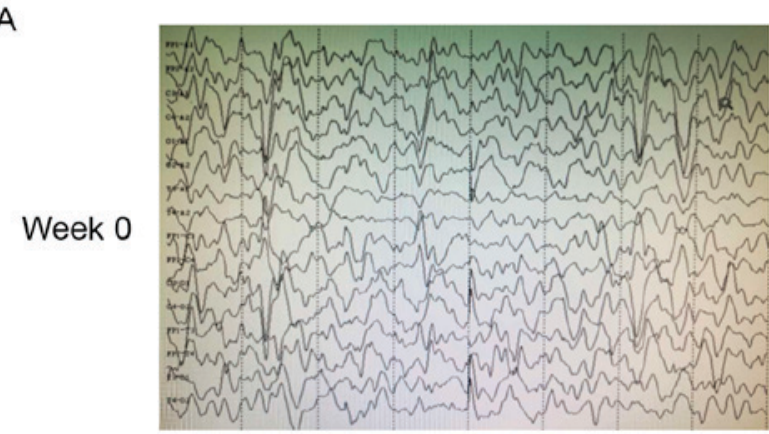

B

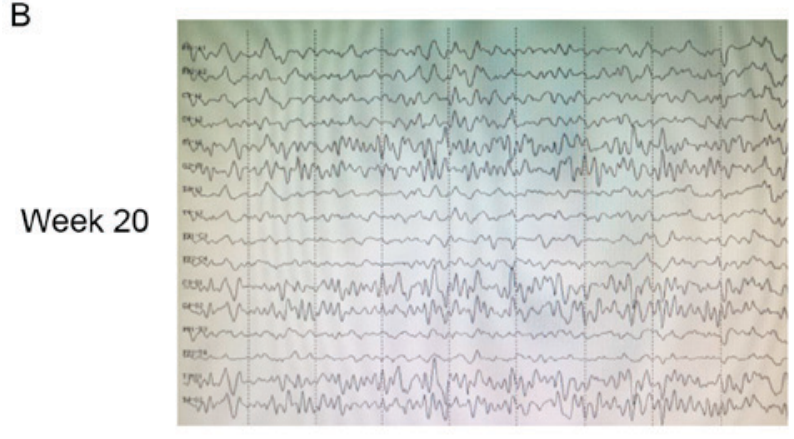

C

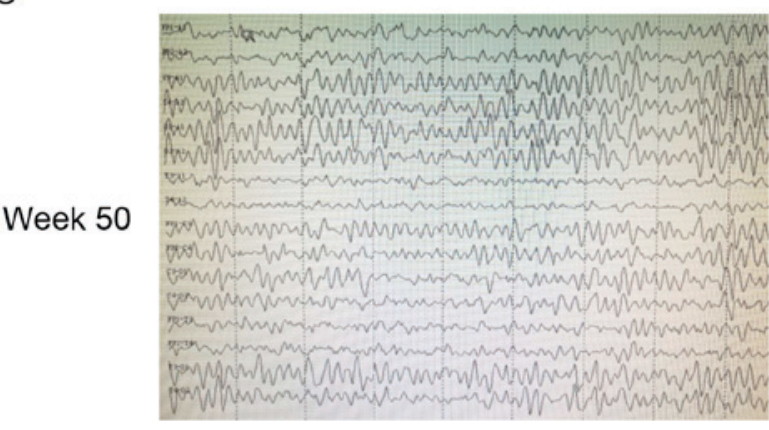

Figure 3. LEV administration improves EEG abnormalities. EEGs were performed at (A) 1-2 days (week 0) after patients became afebrile and at (B) week 20 and (C) week 50 after levetiracetam administration in patients with febrile seizure. EEG, electroencephalogram.

intermittent LEV therapy is safe for FS patients as a clinical therapy.

In the past two decades, many studies have investigated the prevention of FS (14,21,23-25), however, few of these studies have evaluated the therapeutic effect of oral LEV. In several animal models, LEV has been shown to be a highly effective antiepileptic drug against partial and generalized seizures $(26,27)$. A randomized clinical trial by $\mathrm{Hu}$ et al (17) demonstrated a significant reduction in FS recurrence with intermittent oral LEV. In the chronic phase of acute encephalitis with refractory, repetitive partial seizures, administration of LEV (750-1,500 mg/ kg) has been shown to reduce seizure frequency by $>75 \%$ for 5 to 18 months (28). However, detailed information, particularly suitable LEV dosages, is lacking in the clinic treatment of FS. We initially planned to perform a randomized controlled trial to elucidate the possible treatment options of LEV in patients with FS. In this study, the range of LEV dosage was set at $15-30 \mathrm{mg} / \mathrm{kg}$ 
or a higher concentration when taken twice daily. The use of antipyretic medication, LEV, may reduce the frequency of fever and FS recurrence.

Previous studies have suggested that the incidence of EEG abnormalities in children with FS changes from 2 to $86 \%$ in different populations $(19,29)$. In general, an EEG is not recommended in the routine evaluation of children with FS; however, EEG is often performed by clinicians to evaluate FS, since complex FS is associated with increased risk of development of subsequent epilepsy (19). These findings suggest that the variability of EEGs diagnosis may be due to different courses in FS. Notably, one study proposed that EEG should be considered in all patients with complex FS, particularly those who had multiple or prolonged seizures (30). In our study, we found that LEV administration significantly improved $(\mathrm{P}<0.001)$ EEG abnormalities $17.8 \%(8 / 45)$ as compared with the no treatment group $68.6 \%$ (35/51). Jeong et al (19) indicated that $31 \%$ (41/131) of children with FS have EEG abnormalities, and that multiple seizures within $24 \mathrm{~h}$ are associated with abnormal EEGs. In the present study, whether clinical variables are associated with abnormal EEGs in children with FS were also investigated. The findings demonstrated that age and duration of seizure had no apparent association with abnormal EEGs. However, family history of FS was shown to be significantly associated with abnormal EEGs. In a previous study of 676 children with FS, focal seizures and seizures lasting $>15$ min were associated with abnormal EEG findings (31). Therefore, the outcome may be depend partly on the number of patients.

In conclusion, the present findings demonstrated that oral LEV was effective in preventing FS recurrence and the frequency of fever; therefore, we propose the use of oral LEV as a preventive therapy for FS. Furthermore, our findings suggested that LEV administration significantly improved $(\mathrm{P}<0.001)$ EEG abnormalities, which may be used as a clinical monitoring index for LEV treatment in patients with FS.

\section{Acknowledgements}

This study was supported by Science and Technology Plan Projects of Qinhuangdao, China (grant no. 201401A093).

\section{References}

1. Steering Committee on Quality Improvement and Management, Subcommittee on Febrile Seizures American Academy of Pediatrics: Febrile seizures: Clinical practice guideline for the long-term management of the child with simple febrile seizures. Pediatrics 121: 1281-1286, 2008.

2. Vestergaard M, Obel C, Henriksen TB, Christensen J, Madsen KM, Ostergaard JR and Olsen J: The Danish National Hospital Register is a valuable study base for epidemiologic research in febrile seizures. J Clin Epidemiol 59: 61-66, 2006.

3. Annegers JF, Hauser WA, Shirts SB and Kurland LT: Factors prognostic of unprovoked seizures after febrile convulsions. $\mathrm{N}$ Engl J Med 316: 493-498, 1987.

4. Han Y, Qin J, Chang X, Yang Z, Tang X and Du J: Hydrogen sulfide may improve the hippocampal damage induced by recurrent febrile seizures in rats. Biochem Biophys Res Commun 327: 431-436, 2005.

5. Zhao Y, Han Y, Bu DF, Zhang J, Li QR, Jin HF, Du JB and Qin J: Reduced AKT phosphorylation contributes to endoplasmic reticulum stress-mediated hippocampal neuronal apoptosis in rat recurrent febrile seizure. Life Sci 153: 153-162, 2016.
6. Rajab E, Abdeen Z, Hassan Z, Alsaffar Y, Mandeel M, Al Shawaaf F, Al-Ansari S and Kamal A: Cognitive performance and convulsion risk after experimentally-induced febrile-seizures in rat. Int J Dev Neurosci 34: 19-23, 2014.

7. Rosman NP, Colton T, Labazzo J, Gilbert PL, Gardella NB, Kaye EM, Van Bennekom C and Winter MR: A controlled trial of diazepam administered during febrile illnesses to prevent recurrence of febrile seizures. N Engl J Med 329: 79-84, 1993.

8. van Stuijvenberg M, Derksen-Lubsen G, Steyerberg EW, Habbema JD and Moll HA: Randomized, controlled trial of ibuprofen syrup administered during febrile illnesses to prevent febrile seizure recurrences. Pediatrics 102: E51, 1998.

9. Patel N, Ram D, Swiderska N, Mewasingh LD, Newton RW and Offringa M: Febrile seizures. BMJ 351: h4240, 2015.

10. Strengell T, Uhari M, Tarkka R, Uusimaa J, Alen R, Lautala P and Rantala H: Antipyretic agents for preventing recurrences of febrile seizures: Randomized controlled trial. Arch Pediatr Adolesc Med 163: 799-804, 2009.

11. Salehiomran M, Hoseini SM and Ghabeli Juibary A: Intermittent Diazepam versus continuous phenobarbital to prevent recurrence of febrile seizures: A randomized controlled trial. Iran J Child Neurol 10: 21-24, 2016.

12. Hirtz D, Berg A, Bettis D, Camfield C, Camfield P, Crumrine P, Gaillard WD, Schneider S and Shinnar S; Quality Standards Subcommittee of the American Academy of Neurology; Practice Committee of the Child Neurology Society: Practice parameter: Treatment of the child with a first unprovoked seizure: Report of the quality standards subcommittee of the American Academy of Neurology and the Practice Committee of the Child Neurology Society. Neurology 60: 166-175, 2003.

13. Oluwabusi T and Sood SK: Update on the management of simple febrile seizures: Emphasis on minimal intervention. Curr Opin Pediatr 24: 259-265, 2012.

14. Masuko AH, Castro AA, Santos GR, Atallah AN, do Prado LB, de Carvalho LB and do Prado GF: Intermittent diazepam and continuous phenobarbital to treat recurrence of febrile seizures: A systematic review with meta-analysis. Arq Neuropsiquiatr 61: 897-901, 2003.

15. Pavlidou E, Tzitiridou M and Panteliadis C: Effectiveness of intermittent diazepam prophylaxis in febrile seizures: Long-term prospective controlled study. J Child Neurol 21: 1036-1040, 2006.

16. Yang Y, Zheng F, Xu X and Wang X: Levetiracetam versus phenytoin for seizure prophylaxis following traumatic brain injury: A systematic review and meta-analysis. CNS drugs 30: 677-688, 2016.

17. Hu LY, Zou LP, Zhong JM, Gao L, Zhao JB, Xiao N, Zhou H, Zhao M, Shi XY, Liu YJ, et al: Febrile seizure recurrence reduced by intermittent oral levetiracetam. Ann Clin Transl Neurol 1: 171-179, 2014.

18. Xu JC, Shen J, Shao WZ, Tang LJ, Sun YZ, Zhai XF, Qi L, Li J and Zheng JY: The safety and efficacy of levetiracetam versus phenytoin for seizure prophylaxis after traumatic brain injury: A systematic review and meta-analysis. Brain Inj 30: 1054-1061, 2016.

19. Jeong KA, Han MH, Lee EH and Chung S: Early postictal electroencephalography and correlation with clinical findings in children with febrile seizures. Korean J Pediatr 56: 534-539, 2013.

20. Sokol DK, Demyer WE, Edwards-Brown M, Sanders S and Garg B: From swelling to sclerosis: Acute change in mesial hippocampus after prolonged febrile seizure. Seizure 12: 237-240, 2003

21. Verrotti A, Latini G, di Corcia G, Giannuzzi R, Salladini C, Trotta D and Chiarelli F: Intermittent oral diazepam prophylaxis in febrile convulsions: Its effectiveness for febrile seizure recurrence. Eur J Paediatr Neurol 8: 131-134, 2004.

22. Khosroshahi N, Faramarzi F, Salamati P, Haghighi SM and Kamrani K: Diazepam versus clobazam for intermittent prophylaxis of febrile seizures. Indian J Pediatr 78: 38-40, 2011.

23. Ba-Diop A, Marin B, Druet-Cabanac M, Ngoungou EB, Newton CR and Preux PM: Epidemiology, causes, and treatment of epilepsy in sub-Saharan Africa. Lancet Neurol 13: 1029-1044, 2014.

24. Sadarangani M, Seaton C, Scott JA, Ogutu B, Edwards T, Prins A, Gatakaa H, Idro R, Berkley JA, Peshu N, et al: Incidence and outcome of convulsive status epilepticus in Kenyan children: A cohort study. Lancet Neurol 7: 145-150, 2008. 
25. McIntyre J, Robertson S, Norris E, Appleton R, Whitehouse WP, Phillips B, Martland T, Berry K, Collier J, Smith S and Choonara I: Safety and efficacy of buccal midazolam versus rectal diazepam for emergency treatment of seizures in children: A randomised controlled trial. Lancet 366: 205-210, 2005.

26. Ahishali B, Kaya M, Orhan N, Arican N, Ekizoglu O, Elmas I Kucuk M, Kemikler G, Kalayci R and Gurses C: Effects of levetiracetam on blood-brain barrier disturbances following hyperthermia-induced seizures in rats with cortical dysplasia. Life Sci 87: 609-619, 2010.

27. Cilio MR, Bianchi R, Balestri M, Onofri A, Giovannini S, Di Capua $\mathrm{M}$ and Vigevano F: Intravenous levetiracetam terminates refractory status epilepticus in two patients with migrating partial seizures in infancy. Epilepsy Res 86: 66-71, 2009.
28. Ueda R, Saito Y, Ohno K, Maruta K, Matsunami K, Saiki Y, Sokota T, Sugihara S, Nishimura Y, Tamasaki A, et al: Effect of levetiracetam in acute encephalitis with refractory, repetitive partial seizures during acute and chronic phase. Brain Dev 37: 471-477, 2015.

29. Joshi C, Wawrykow T, Patrick J and Prasad A: Do clinical variables predict an abnormal EEG in patients with complex febrile seizures? Seizure 14: 429-434, 2005.

30. Kim H, Byun SH, Kim JS, Lim BC, Chae JH, Choi J, Kim KJ, Hwang YS and Hwang H: Clinical and EEG risk factors for subsequent epilepsy in patients with complex febrile seizures. Epilepsy Res 105: 158-163, 2013.

31. Sofijanov N, Emoto S, Kuturec M, Dukovski M, Duma F, Ellenberg JH, Hirtz DG and Nelson KB: Febrile seizures: Clinical characteristics and initial EEG. Epilepsia 33: 52-57, 1992. 